(2)

\title{
Algumas raízes do anti- semitismo no Brasil ou um outro olhar sobre Paris
}

\author{
EVA ALTERMAN BLAY
}

RESUMO: A construção da cultura passa por múltiplas influências culturais. A dinâmica cultural desmente pretensas posições etnocêntricas. Ao longo do tempo a história brasileira se viu vinculada a vários sistemas socioculturais e, nos dois últimos séculos, às influências ibérica, africana e indígena houve intensa incorporação da cultura francesa e anglo-saxônica que somadas, moldaram, em grande parte, nossos corações e mentes. Neste trabalho se focaliza a influência da cultura e do catolicismo conservador francês na formação do anti-semitismo brasileiro. A partir da análise da iconografia religiosa se observará uma das fontes da construção da diabolização do judeu no imaginário popular e culto. A construção da exclusão social dos judeus franceses e sua deportação para campos de concentração será observada através de um roteiro pelo Marais, o bairro judaico de Paris. A arquitetura concentracionista de Corbusier completa o quadro da exclusão social. Todos estes elementos, reunidos, permitem entender, em parte, como foi sendo construída a imagem do judeu imigrante no Brasil expressa por vários autores.

\section{Velhas e novas hegemonias econômicas e culturais}

cusa-se a globalização pela construção de culturas homogêneas. $\mathrm{Na}$ verdade, a acusação se refere à expansão da influência cultural norte-americana. O fenômeno não é novo: ao lado de hegemonias econômicas a cultura absorve inúmeras outras influências, mesclando-as às
PALAVRAS-CHAVE: anti-semitismo, campo de concentração, Drancy, França.

Professora do Departamento de Sociologia da FFLCH - USP 


\section{1. "A Sinagoga vencida"}

Imagem do lado direito da fachada da Catedral de Notre Dame, Paris.

2. Fachada da Catedral de Notre Dame, Paris

Esta pesquisa foi realizada durante 1996, na França, com bolsa de Pós Doutorado da Fapesp. Parte deste trabalho foi apresentado no Congresso Afro-Luso-Brasileiro. Porto, 2000 e no II Encontro Brasileiro de Estudos Judaicos, Rio de Janeiro, 1999.

\footnotetext{
${ }^{1}$ Claro, não nos referimos a culturas indígenas isoladas.
}

preexistentes raízes locais. Basta um rápido olhar sobre o passado para desmentir a possibilidade de se constituir um sistema cultural autóctone seja no ocidente ou oriente ${ }^{1}$.

No caso brasileiro, de tempos em tempos despontam debates puristas sobre a música, pintura, teatro, como se o Brasil ou qualquer ou-

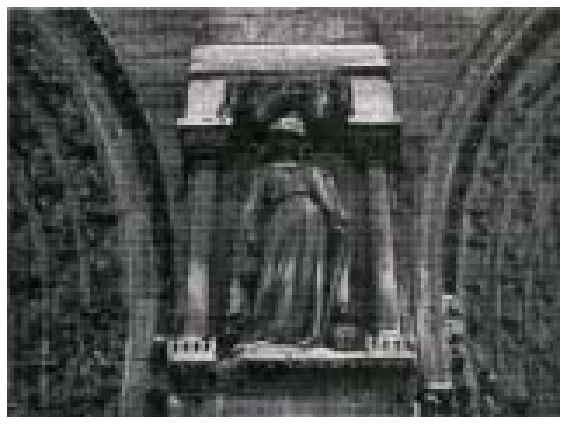

tro país, nação ou povo pudesse sobreviver isoladamente. Isto não significa que haja um internacionalismo que homogeinize as diferentes culturas mas sim que, na construção da história social, são absorvidas inúmeras influências em decorrência de hegemonias econômicas, políticas e culturais.

Ao longo do tempo a sociedade brasileira se viu vinculada a vários sistemas socioculturais e, nos dois últimos séculos, houve intensa influência francesa e anglo-saxônica que moldou, em grande parte, nossos corações e mentes.

Para destrinchar o caminho desta penetração cultural examinemos nossas próprias trajetórias. Como muitos brasileiros e brasileiras de minha geração e classe social estudei em escola pública - na época, anos

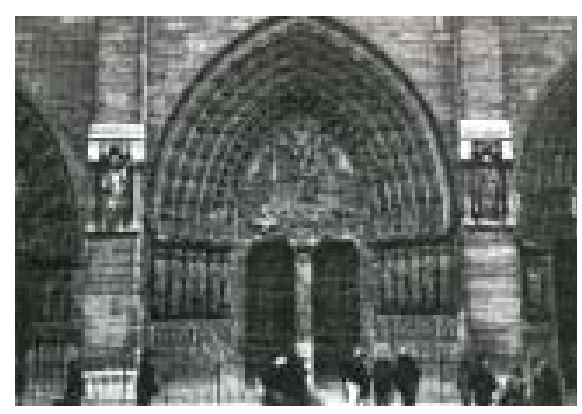
50 , considerada a melhor - onde aprendi a respeitar a cultura, a arte, a literatura francesas. $\mathrm{Na}$ escola pública até o fim dos anos 70 se estudava, no ginásio, o francês desde o primeiro ano e o inglês a partir do $2^{\circ}$. Aprendi a cantar a Marselhesa no original. Através da educação formal, instalava-se um filtro ideológico cultural que selecionava fatos visíveis e obscurecia outros. A relação de subordinação colonial mantida com tudo que viesse da França permitia, a nós brasileiros e brasileiras, estabelecer uma escala de valores que determinava nossa visão do mundo e do Brasil. A rebelião dos artistas da Semana de 1922 fora uma pálida reação ao poderoso centro econômico hegemônico francês, solidamente infiltrado em todos os campos da vida quotidiana: a roupa, a comida, a arquitetura, a arte, a língua, os valores...

A dominação ideológico-cultural é sutil e complexa. Junto à cultura francesa, aparentemente laica e racionalista, veio uma vertente católica que influenciou parcela preponderante do pensamento brasileiro.

Creio que descobriremos muito do que aprendemos no Brasil se olharmos, de novo, as catedrais, alguns monumentos e as próprias ruas de Paris.

Sugiro um roteiro para este novo olhar. 


\section{Da carriére ao gueto}

A presença judaica na França, ou, se preferirem, na Gália, remonta ao período romano. Com a queda de Massada, no ano 73, muitos judeus fugiram do Reino de Israel e vieram se instalar em cidades do sul da França além de outras partes da Europa. Os judeus já estavam há 5 séculos na região quando a recente monarquia francesa se tornou cristã com o batismo de Clovis. Conforme anexações territoriais foram sendo feitas, excluíam-se os judeus e os marcavam com um disco de tecido (rouele) costurado sobre a roupa; posteriormente o disco foi substituído por um chapéu amarelo. Embora estivessem na França há XIII séculos, com Felipe, o Belo (1306), e Carlos V (1394), foram obrigados a viver somente em certas ruas, trancadas à noite. Eram as carrières, antecessoras dos guetos.

Na cidade de Cavaillon, onde havia uma carrière cuja sinagoga é atualmente um pequeno museu, pode ser vista uma chanukia, candelabro de oito braços, do período romano. Diz a história oral que as carrières ficavam fechadas à noite para "proteger" os judeus evitando que cristãos entrassem para atacá-los.

Era o inverso, os judeus ficavam presos no "gueto", não podiam circular à noite para evitar eventuais encontros amorosos ou mesmo qualquer contato não controlado pelas autoridades locais.

A situação era diferente em Avignon quando lá se instalou a sede do papado contrário a Roma. Tinham proteção e liberdade de circulação e, em troca, custeavam os gastos militares do considerado antipapa.

Em praticamente todas as cidades francesas são encontradas as "Ruas dos Judeus", indicativas da restrição imposta à moradia que, com algumas exceções, duraram até 1790-1791² quando os judeus foram emancipados. Este fenômeno, a Rua dos Judeus, é encontrado em inúmeros países da Europa e inclusive no Brasil.

\section{A didática da exclusão}

Vários mecanismos foram usados para ensinar aos cristãos porque os judeus deveriam ser excluídos. Visitando as monumentais catedrais se tem uma noção da didática do anti-semitismo medieval e renascentista. Ali estão os símbolos da vitória da Igreja e da derrota da Sinagoga. Os crentes eram e são recebidos à porta por esculturas na forma de mulheres, uma altiva, portando as tábuas da lei, a coroa e o cetro, simboliza a "Igreja vencedora"; a outra, de cabeça baixa, tem nas mãos as tábuas da lei quebradas e colocadas de cabeça para baixo, sem coroa ou cetro, tem os olhos vendados, simbolizando a cegueira pois não enxergam a verdade do cristianismo. São a representação da "Sinagoga", vencida.

A mais agressiva didática visual está nas gárgulas, figuras de pedra que envolvem as calhas das igrejas, na forma de porcas ou porcos, mantendo relações sexuais com seres humanos, os judeus (Raphaël e Weyl, 1977).

Era a excelência da forma didática para ensinar a "verdade" cristã
${ }^{2}$ Embora a Declaração dos Direitos do Homem e do Cidadão seja de 26 de agosto de 1789 , houve duas datas para a igualdade dos judeus: 28 de janeiro de 1790 igualdade para os judeus de origem portuguesa, espanhola e de Avignon; 27 de setembro de 1791, a Assembléia emancipa os judeus da Alsacia e da Lorena tornando então emancipados todos os judeus da França (cf. Barnavi, 1995, p. 160). 
aos fiéis de todas as idades que freqüentavam a missa. $\mathrm{O}$ quadro se completava com os trípticos e pinturas onde o inferno era representado por figuras de chifre e rabo, o diabo associado aos judeus.

A mídia da época - a iconografia eclesiástica - desempenhava seu papel ao veicular uma imagem do judeu herege, dissoluto, ligado ao inferno. Considere-se que, por pelo menos cinco séculos, estas representações eram as únicas formas a ensinar os "verdadeiros" valores.

No entanto, em todas estas regiões, os judeus se consideravam absolutamente franceses e muitos tinham se convertido ao catolicismo.

\section{Do "gueto" ao Marais}

Muitos judeus, graças às atividades econômicas de produção e de comércio, já viviam fora das carrières quando veio a emancipação em 1791. Algumas famílias estavam instaladas em Nancy, Estrasburgo e Paris. São sobretudo estes segmentos que, a partir do séc. XIX, passaram a se auto-definir como "franceses de crença israelita"; até hoje não se dizem judeus. Ao assim se identificarem tais segmentos pretendiam (e pretendem ainda hoje) acentuar a diferença entre eles, os antigos, e os imigrantes da Europa Oriental de meados do séc. XIX e primeiras décadas do XX. A maioria destes imigrantes veio em busca de emprego e fugindo dos pogrons da Europa Oriental. Eram judeus operários e foram predominantemente para Paris em busca das oficinas de confecção que necessitavam de força de trabalho e pagavam bem.

Em Paris, como disse Mandel: "Não foram morar no gueto, pois este foi substituído pelos bairros operários onde vivem judeus proletários" (Mandel,1950 apud Green,1985, p. 7). Foram morar no Marais.

As condições de exploração levaram à organização de um movimento operário judaico que foi responsável por inúmeras greves (cf. Green, 1985, p. 111-17). Concomitantemente criaram escolas e centros de ensino profissional. Finalmente se articularam para a criação de um movimento sindical.

O Marais foi o cenário dessas lutas cujas marcas ainda estão vivas. Funcionam as escolas para trabalhadores ${ }^{3}$, há habitações modestas, inúmeras minúsculas sinagogas, sedes de antigos sindicatos.

Em todos esses imóveis estão também placas alusivas às deportações para Drancy e para Auschwitz.

Sentirem-se e agirem como franceses, participarem de guerras como a de 14, não impediu que fossem perseguidos durante a ocupação da $2^{a}$ Guerra. Sob o pretexto de conter a expansão de Hitler pela França, o

3 École de Travail. 4 bis Rue des Rosiers. Paris.
General Pétain fez um tratado com o regime nazista e instalou seu governo em Vichy. O braço nazista passou a utilizar a polícia francesa para fazer o mesmo serviço que a SS fazia na Alemanha e em outros países dominados: a caça, espoliação dos bens e destruição dos judeus. 


\section{Marais e Bom Retiro}

O charmoso Marais, em Paris, é um bairro muito visitado por turistas inclusive brasileiros. Nele está a Place de Voges e vários museus como o Carnavalet, o Hotel de Sully, o museu Picasso. Na terra dos museus, curiosamente, apenas em 1998 foi instalado um Museu Judaico ${ }^{4}$ não por acaso no Marais.

No séc. XVII o Marais foi a residência da realeza; após a revolução de 1789 foi ocupado pela "plebe". No fim do séc. XIX e começo do XX ficou conhecido como um bairro judaico pois lá imigrantes judeus da Europa Oriental se instalaram em precárias habitações e inúmeras oficinas artesanais. O olhar dos franceses sobre a pobreza dos imigrantes judeus é fielmente descrita nas palavras de Férenzy: "Os únicos judeus com quem aliás eu tinha tido contacto até então (1910) eram os infelizes refugiados da Russia, da Polonia e da Rumania, que pululam no Quarto Districto da capital, onde eu por muito tempo morei e sua desdita, juntamente com o fiel apêgo ao seu culto, eram de molde a nos tornar sympaticos. ...Terminada a guerra vim fixar meu domicilio na Alsacia. Sabe-se que os judeus aqui são numerosos. Mas, não são os piolhentos (sic) do bairro parisiense do Marais" (Férenzy, 1939, p. 16-17). Ferenzy é o autor de Les Juifs et nous les Chretiens, livro escolhido pela Bibliotheca do Pensamento Catholico, sob a direção de José Carlos de Macedo Soares, traduzido para o português e que tinha o objetivo de se contrapor ao anti-semitismo nazista. Como se vê muitos valores e preconceitos se mesclam apesar da indiscutível vontade de se contrapor à perseguição nazista.

Semelhante ao Marais, o Bom Retiro, em São Paulo, foi o bairro de maior concentração de judeus operários no início do séc. XX. Embora os judeus tivessem chegado décadas antes, e se espalhado pela cidade toda, o Bom Retiro ficou conhecido como o "bairro judeu" independentemente da enorme presença de operários italianos e de outras nacionalidades. Morar no Bom Retiro era (e é) uma marca de identidade étnica.

Em algumas ruas do Bom Retiro se instalaram casas de prostituição. O interventor Ademar de Barros, sob pretexto de "limpar" a cidade, ampliou o espaço de prostituição transferindo-as compulsoriamente para lá.

É possível que estes fatores tenham fortalecido uma identificação socialmente desclassificadora o que levou gerações seguintes a saírem do bairro.

A dinâmica urbana é fortemente movida pela especulação imobiliária. No caso do Marais, na segunda metade do séc. XX, foi "recuperado" e ocupado pela classe média alta.

Atualmente lá estão, em edifícios do séc. XVI ou XVII, antiquários, requintados, ateliers de alta costura, ruas de sofisticado comércio varejista mas também alto atacado e açougues kasher, restaurantes de comida judaica da Europa Oriental e do Oriente Médio. Várias antigas sinagogas de todos os tamanhos convivem com igrejas católicas. Escolas judaicas estão ao lado de escolas laicas e colégios particulares.

\footnotetext{
4 Anteriormente havia uma modesta instalação de um Museu Judaico (Musée d'Art Juif de Paris. 42 Rue des Saules. $18^{\text {ème }}$ ) onde havia também uma pequena sinagoga e uma escola.
} 
Mas não nos confundamos, andemos pelas maravilhosas ruas do Marais, olhando com atenção placas, inscrições em pedra, observemos algumas flores colocadas junto a certas inscrições. Leremos então o testemunho do anti-semitismo e morte de judeus e encontraremos até lápides no meio de pequenos jardins particulares. Comecemos pela

\section{Rue des Rosiers}

A Rue des Rosiers é talvez a mais conhecida do Marais judaico. Lá estão inúmeras lojas de moda ao lado de livrarias e papelarias que vendem jornais judaicos publicados em Paris, em Israel e outras partes da França e do mundo. Há casas de artigos religiosos, discos cantados por judeus do Oriente, da França, de Israel ou da Europa Oriental. Dos vários restaurantes, no "Joe Goldemberg" estão os orifícios dos tiros que, num sangrento atentado, deixaram vítimas fatais, na extensão da guerra entre palestinos, árabes e israelenses.

Andando pela Rue des Rosiers se destacam, para olhos avisados, algumas pequenas placas que guardam a memória dos antigos moradores, exterminados pelo nazismo alemão e francês.

\section{Bis Rue des Rosiers}

Lá ainda hoje funciona a École de Travail instalada em 1852. Ao lado da porta, uma placa de pedra diz:

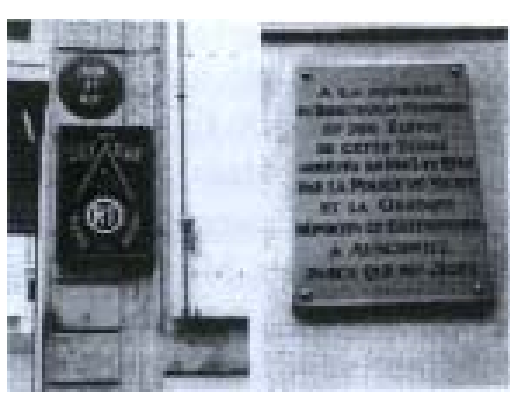

À memória do Diretor do Pessoal e dos alunos desta escola, presos em 1943 e 1944 pela Polícia de Vichy e pela Gestapo, deportados e exterminados em Auschwitz, porque nasceram judeus.

\section{6, Rue des Rosiers}

Na mesma Rue des Rosiers, pare ao lado da porta número 26 e você lerá a placa que informa:

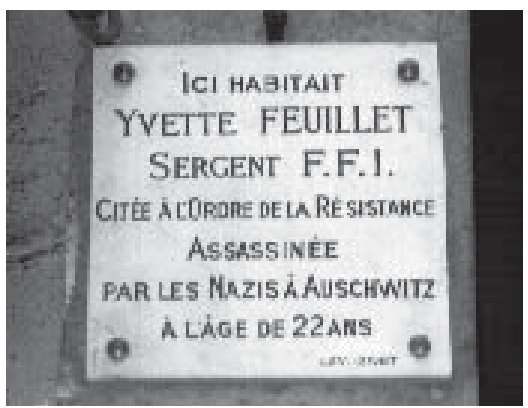

Aqui morou Yvette Feuillet. Sargento da Força Francesa do Interior, merecedora da Ordem da resistência. Assassinada pelos nazistas em Auschwitz aos 22 anos. 


\section{Rue des Rosiers}

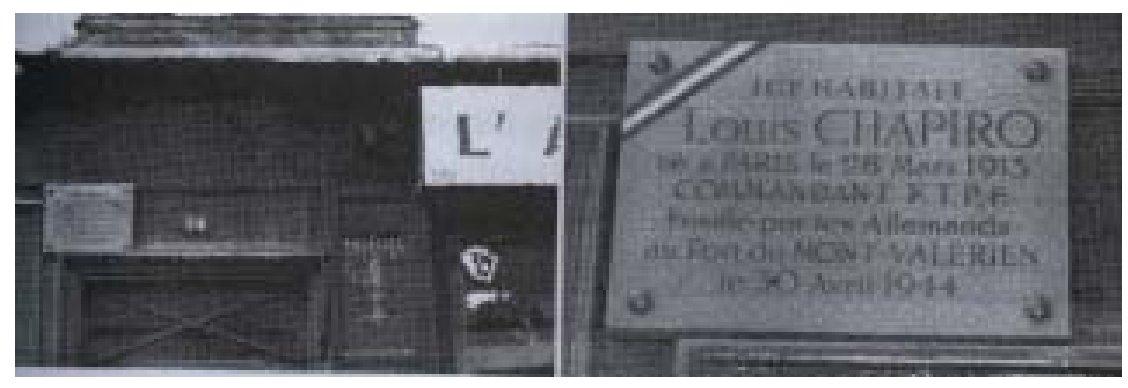

Quase vizinho, no ${ }^{\circ} 34$ da Rue des Rosiers, a placa diz: Aqui moru Louis Chapiro, nascido em Paris no dia 28 de Março de 1915. Comandante da FTPF. Fuzilado pelos Alemães no Forte do Monte Valerio em 30 de abril de 1944.

\section{8/10 Rue des Hospitaliers Saint Gervais}

Um pouco mais adiante, perpendicular à Rue des Rosiers, está a Rue des Hospitaliers Saint Gervais. No nº 8 /10 há uma grande escola primária criada em 1844. Destinava-se a meninos israelitas. Ladeando a grande porta há duas placas de pedra: a da esquerda faz uma homenagem à bravura do seu Direto, Joseph Migneret, que salvou muitas crianças da deportação insurgindo-se contra ordens superiores. Ele fez parte daqueles franceses que resistiram à conivência para eliminar os judeus da França.

Mas a placa da direita informa que 165 crianças dessa mesma escola foram deportadas

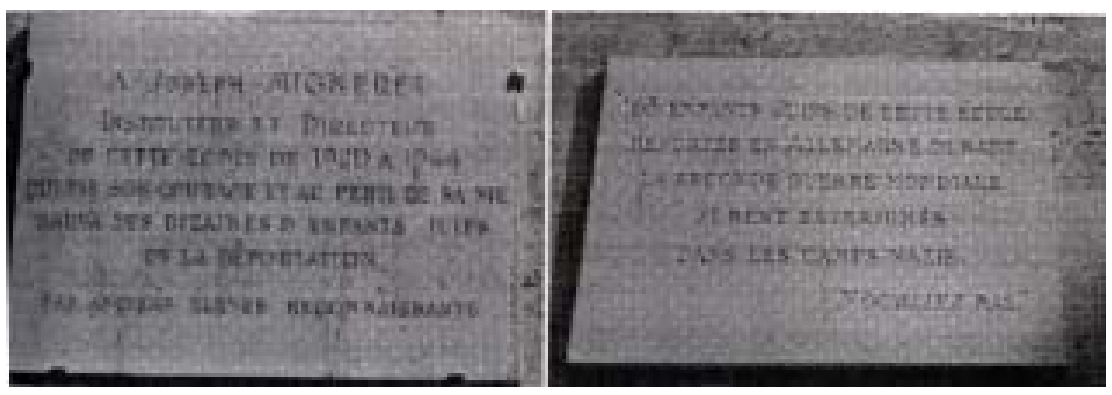

\section{Rue desÉcouffes}

Vamos a outra rua perpendicular à Rue des Rosiers, a Rue des Écouffes. Lá, no nº 18 está a Fundação Roger Fleischman, criada em 1931 para homenagear o jovem Roger que morreu aos 19 anos. Dizem que era um $t s a d i k$, um santo. Neste local de oração se ensinam às crianças a leitura da Torá. Lá moravam a Sra. Engros com seus três filhos. Todos foram fuzilados pelos nazistas, lembra a placa colocada do lado esquerdo de quem entra. 


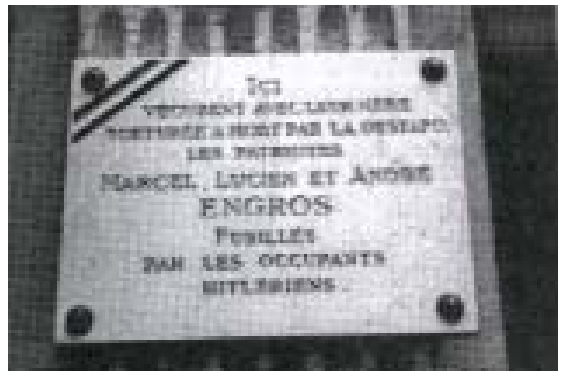

Aqui viveram com sua mãe, torturada até a morte pela Gestapo, os patriotas Marcel, Lucien e Andre Engros, fuzilados pelos ocupantes hitleristas.

\section{0-12 da Rue des DeuxPonts}

Se estivermos com vontade de espairecer um pouco, procurar um lindo lugar à beira do Sena e decidir ir a pé para a Île de Saint Louis, muito próxima, nem assim se vai escapar destas tristes marcas. No 10-12 da Rue des Deux Ponts está uma discreta indicação: Fundação Fernand Halphen fundada em 1926. À direita a fatídica placa:

\section{Rue Egignard}

À memória dos 112 habitantes deste prédio, dos quais 40 eram pequenas crianças, deportados e mortos nos campos alemães em 1942

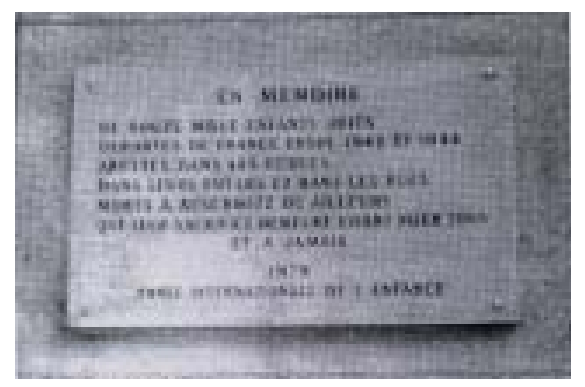

As surpresas se sucedem. Caminhando de volta para a Rue Saint Paul, a linda rua dos antiquários, em meio a inúmeras vitrines há também estreitíssimas travessas, escondidas entradas para pátios e passagens para outras ruas. Entre elas a R. Egignard. Terá talvez uns 20 metros de comprimento.No fundo uma casa alta e um pequeno jardim no qual foi colocada a seguinte lápide

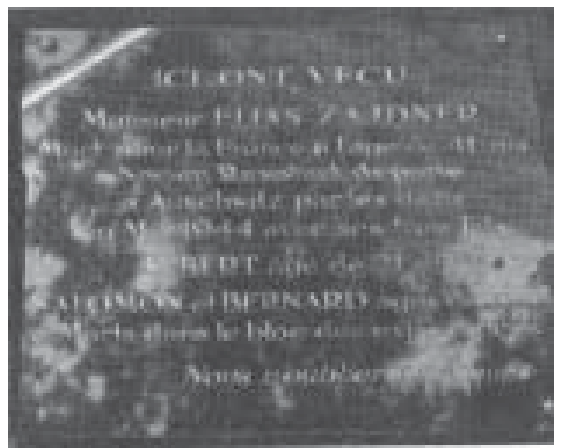

Aqui viveu o Senhor Elias Zajdner, morto pela França aos 41 anos. Antigo resistente foi deportado para Auschwitz pelos nazistas em Maio de 1944 com seus três filhos Albert de 21 anos, Salomom e Bernard de 15 anos mortos no setor de experiências. Nós jamais os esqueceremos. 
Da família Zajdner restou uma filha que nunca conseguiu recuperar a casa confiscada pelo governo Vichy e que continuou ocupada pelos governos posteriores. Ela levou 50 anos para obter autorização para colocar a lápide na antiga casa de seu pai. É apenas mais um dos casos em que as propriedades dos judeus foram confiscadas pelo governo Vichy e nunca mais devolvidas (cf. Vital-Durand, 1996). As notícias sobre estas indevidas apropriações foram fartamente noticiadas pela imprensa em 1996 e, em 1999, quando algumas restituições começaram a ser feitas, verificou-se que, afinal, os judeus franceses não eram os magnatas que muitos supunham.

\section{Rue Buffalt}

Mas não é só no Marais que encontramos estas memórias. Não muito longe da Ópera, numa travessa da Rue La Fayette e perto do Faubourg de Montmartre, há um alto prédio de pedra branca onde funcionava uma escola laica para meninas. No n 32 da Rue Buffault há uma placa com a seguinte inscrição:

\section{Em memória}

Doze mil crianças judias presas, nas escolas, em suas casa e nas ruas, foram deportadas da França entre 1942 e 1944 e mortas em Auschwitz ou outros lugares. Que seu sacrifício permaneça vivo para todos e para sempre. 1979 Ano Internacional da Criança.

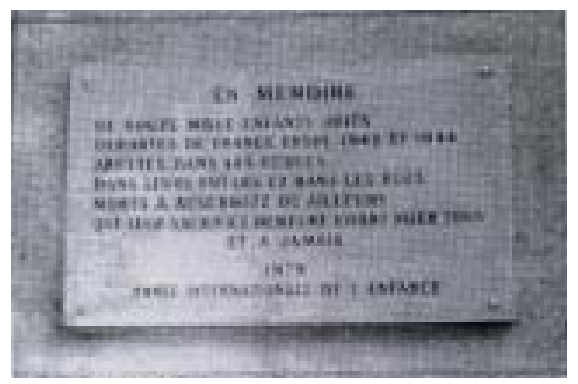

Estes marcos são encontrados também em outras cidades. Citarei apenas uma, que vi em Avignon, logo ao lado da Sinagoga, 4 Place Jerusalém:

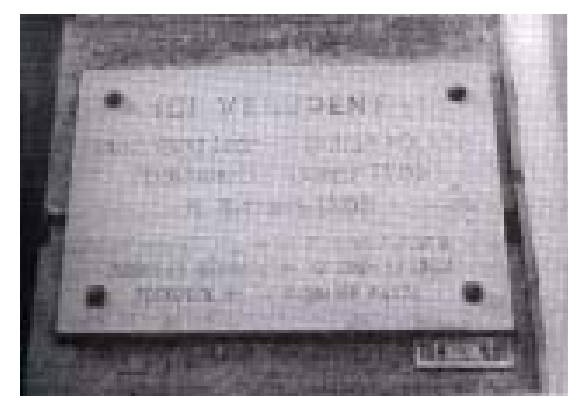

Aqui viveram a Viúva Sra. Lucien Bernheim nascida Lyon, Srta. Andrée Lyon, M. Raymond Lyon, mebros de antiga e honorável família de Avignon. Mortos quando deportados em 1943 e 1944. Vítimas da barbárie nazista.

\section{O campo de concentração de Drancy}

Afinal como foi feita uma deportação tão grande? Como foram reunidas tantas crianças, jovens, mulheres e homens adultos, velhos, todos judeus e de que modo foram eles transferidos para Auschwitz? 
Drancy e outros campos de concentração franceses são a resposta. Pelo Tratado de Cooperação Vichy x Hitler criou-se na França o Comissariat General aux Questions Juives e foram instalados campos onde os judeus tinham de ficar concentrados. Bastava ser judeu, não importava se eram franceses ou de outra nacionalidade. Foram mais de 20 campos.

Autoridades têm usado a forma eufemísitca"campos de passagem" para se referir aos campos de concentração franceses, alegando que neles não havia fornos crematórios. No entanto, o procedimento era o seguinte: judeus franceses ou judeus estrangeiros eram obrigados a deixar suas respectivas casa e eram aprisionados nestes campos guardados pela polícia francesa. Cercas evitavam que fugissem. Perdiam todos os seus bens.

A partir destes campos eram transferidos e concentrados em um deles, o de Drancy, "Camp de Juifs" (Direction de la Policie Generale, 1943) de onde saía um trem diretamente para Auschwitz.

Os comboios eram numerados e havia listas com os nomes de todos os passageiros que podem ser consultadas no livro de Klarsfeld (1978) Memorial da deportação dos judeus da França de 1942 a 1944, elaborado a partir da documentação francesa nazista. Os campos franceses eram solidários à execução dos prisioneiros muitos dos quais morriam no próprio território francês, especialmente bebês e crianças de pouca idade.

Klarsfeld relacionou 73 comboios dos quais 59 saíram de Drancy, 8 de Pithiviers, um de Beaume-la-Rolande, um de Compiegne e um de Angers. Faltam três listas.

Dos 75.721 deportados da França retornaram apenas 1.518.

Georges Etlin, um judeu prisioneiro, foi encarregado pelas autoridades do Campo de Drancy a elaborar listas dos prisioneiros por nacionalidade. Em maio de 1943 lá havia 2.476 prisioneiros, 1.487 homens e 989 mulheres, crianças e velhos. Destes 1545 eram franceses e 931 estrangeiros. Nesta relação há dois brasileiros. Quem seriam?

Em outro trabalho que escrevi para o $\mathrm{n}^{\circ} 1$ da Revista Tempo Social (Blay, 1989) referi-me a vários casos de deportação de judeus do Brasil para a Europa nazista e fascista. Todos conhecem o célebre caso de Olga Benário mas poucos se referem aos casos de Jenny Gleizer, do Sr. Gutnik e outros. Tentei conseguir com Rivka Gutnik os nomes dos outros deportados mas ela sempre alegava que não sabia. Talvez não soubesse, talvez não quisesse dizer pois o medo ficou com ela e com outros militantes até a morte. Procurei encontrar na França, através de documentos, indicação dos deportados.

Os dois brasileiros que constam da lista poderiam ser identificados se eu consultasse as listas originais guardadas no Carton F9 5579, nos Archives Nationales de Paris. Surpreendentemente foi impossível obter autorização para consultar esta caixa. O funcionário dos Archives que nos autoriza (ou não) a entrar após fazer inúmeras perguntas me informou que os documentos não estavam disponíveis - 50 anos depois! Disse-me que eu não estava autorizada 
a publicar, sob pena de ser processada, mesmo aqueles documentos que pesquisei no Centre de Documentation Juive Contemporaine. Ameaçou-me e me dissuadiu de pedir autorização garantindo que não a obteria.

\section{De Drancy para Auschwitz}

Drancy fica a uns 20 minutos do centro de Paris. Na Porte de Pantin, toma-se o ônibus 151 que em poucos minutos nos deixa no ex-campo, hoje moradia de uma população imigrada da África do Norte e seus descendentes.

Drancy, antiga Ville de la Muette, foi construída por Le Corbusier - que tanto influenciou a arquitetura brasileira dos anos 30, 40 - para ser uma cidade operária modelo. Ocupava um terreno de uns 15.000 m quadrados, as edificações formavam a figura $\mathrm{U}$ o que foi considerado um modelo da arquitetura "concentracionista" por historiadores e arquitetos. Explica-se: bastava

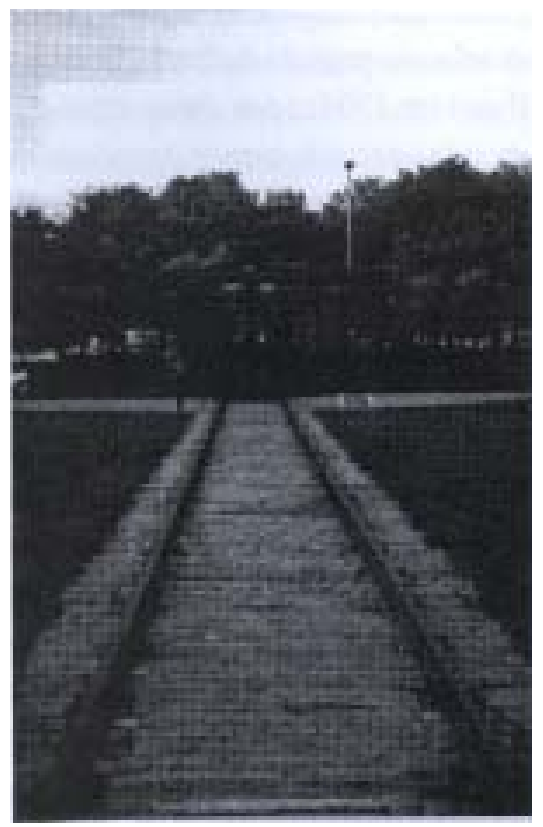
colocar uma cerca e se fechava a entrada do U aprisionando os que lá viviam. Foi exatamente o que aconteceu no governo colaboracionista de Pétain. Arames farpados, metralhadoras e guardas franceses aprisionaram os judeus franceses e de outras nacionalidades.

Os documentos da "Prefecture de Police" informavam que em Drancy havia 4.500 lugares. Lá se jogaram homens, mulheres, crianças muito pequenas. Evidentemente não havia camas, fraldas, nem banheiros suficientes. Algumas pessoas da vizinhança francesa, não conscientes dos fatos políticos, reclamavam do tratamento desumano dado às crianças e chegaram a escrever ao General Pétain, supondo inocentemente que ele desconhecia o que se passava no campo.

Recentemente foi reencontrado um túnel construído para fuga lamentavelmente descoberto a tempo e que não pode evitar a transferência dos prisioneiros para o vagão de trem que rumaria para Auschwitz.

Antigos deportados que voltaram à França organizaram uma sociedade, o "Conservatoire Historique du Camp de Drancy", para conservar a memória da deplorável deportação; fazem eventos, convidam jovens estudantes para conhecer a história do antigo campo visando educá-los para a democracia.

Mesmo em 1996 não conseguiram apoio governamental para restaurar o túnel da fuga.
3. O vagão da deportação dos judeus a partir do Campo de Drancy 


\section{Brasil e França}

A influência da cultura francesa no Brasil foi além da Academia, impregnou a cultura erudita e a popular, usos e costumes, gostos e valores. Não é necessário analisar a música popular brasileira, a moda, o cordel, para avaliar a penetração da cultura francesa. Além do já citado francês das escolas secundárias, as aulas no período da fundação da Faculdade de Filosofia da Universidade de São Paulo em 1934, e por alguns anos, eram dadas naquela língua. Certamente não se errará se considerarmos o predomínio cultural francês até uma década depois da Segunda Guerra Mundial. O inglês o foi progressivamente substituindo na medida em que a economia norte-americana se tornava hegemônica.

A religião católica, na versão conservadora francesa, veio junto e se somou ao catolicismo já presente no Brasil. Fortalecia-se a orientação de que os judeus deveriam ser convertidos pois representavam a negação da Igreja, de Cristo, a aliança com o mal, etc. Ordens religiosas, como a de Sion cuja missão no Brasil também era a de converter os judeus, formaram-se com a tarefa de salvação dos judeus - cuja conversão seria premiada com salvação do próprio conversor.

Parcela dos católicos admitia que, apesar das diferenças, os judeus deveriam ser defendidos de atitudes anti-semitas. A já citada Bibliotheca do Pensamento Catholico, sob a direção de José Carlos de Macedo Soares, tinha este objetivo. Em volume daquela coleção, o Padre R.P. Devaux, SuperiorGeral dos Padres Missionários de Nossa Senhora de Sião, diz: "A Igreja catholica sempre teve o costume de rogar pelo povo hebreu, que foi o depositario das promessas divinas até Jesus Christo, não obstante a cegueira desse povo. Além disso, ella o faz por causa dessa mesma cegueira. Obedecendo a este principio de caridade, a Sé Apostolica protegeu esse povo contra injustas oppressões e, ao mesmo tempo que reprova em geral todos os ódios e animosidades entre os povos, condemna, no mais alto grau, o odio contra o povo outro' ora escolhido por deus, odio que hoje é designado ordinariamente pelo nome de antisemitismo". (Decreto do Santo Officio de 25 de março de 1928) (Devaux, 1939, p. 12).

A cegueira dos judeus, simbolicamente esculpida nas imagens de pedra e mármore das Catedrais, reaparece nas expressões com que alguns autores franceses definem os judeus. Apesar da indiscutível boa vontade de muitos, estava-se longe de se aceitar a pluralidade de crenças e valores. Era necessário um grande esforço intelectual para justificar a presença dos "diferentes". Sendo o catolicismo a religião hegemônica no Brasil do séc. XIX e XX, estas questões se tornaram fundamentais e extrapolaram os limites da própria religião. O raio de influência dos valores cristãos atingia imensas camadas da população inclusive os próprios judeus.

Intelectuais brasileiros, como Humberto de Campos, ao defender os judeus ameaçados por Hitler, revelam a distorcida e contraditória imagem que tinham dos judeus. Campos aborda a célebre culpabilidade dos 
judeus que teriam vendido Cristo, ou a suposta valorização do dinheiro. Assim procura compartilhar estas culpas mostrando que são as duas faces da mesma moeda pois "tanto foi criminoso Judas, que vendeu Christo, como os sacerdotes, que o compraram;...A cupidez de Israel não existiria, pois, se não existisse a imprevidência do christão" (Campos, 1933, p.18).

E já que as culpas devem ser divididas, Campos expõe qual deve ser a conduta do governo brasileiro face à expulsão dos judeus da Alemanha nazista: "O Brasil devia, pois, abrir os braços a Israel, na hora em que o perseguem no Velho Mundo....Venham com os livros e com os livros de cheque. E só encontrarão irmãos, - desde, está bem visto, que não venham augmentar o numero de vendedores de moveis a prestações". E conclui: De qualquer modo, aqui fica, e bem alto, o protesto de um escriptor brasileiro contra a perigosa aventura do racismo allemão. Uma perseguição religiosa, em nossos tempos, mesmo ditada por secretas razões economicas, envergonha o seculo. Mas Israel vencerá. Hitler nasceu hontem. Moyses tem quatro mil annos" (Campos, 1933, p. 19).

A imagem da cupidez judaica estava instalada. Apesar dela, ou por causa dela, os judeus não deveriam ser perseguidos e seriam bem vindos ao Brasil.

Da cultura e valores franceses veio tudo, os laicos e fraternos e os anti-semitas e racistas.

Paris continua sendo uma das mais belas cidades do mundo. É um enorme prazer andar por suas ruas, ver construções que marcaram o tempo, a beleza nos museus. A história revela um povo heterogêneo, há os que lutam pela liberdade e o respeito à diferença, e os que discriminam e espoliam os perseguidos. Não se pode andar ingenuamente pelas lindas ruas, continuar bebendo apenas a beleza e ignorando os que foram perseguidos e mortos seja por serem judeus ou por defenderem a liberdade. Paris vale pela resistência.

\section{Recebido para publicação em fevereiro/2001}

BLAY, Eva Alterman. Anti-semitic roots in Brazil or a different view of Paris. Tempo Social; Rev. Sociol. USP, S. Paulo, 13(1): 129-142, May 2001.

ABSTRACT: The construction of culture undergoes a number of cultural influences. Cultural dynamics disavows alleged ethnocentric positions. From the beginning, Brazilian history has been linked to various socio-cultural systems. In the last two centuries, an intense incorporation of French and Anglo-Saxon cultures has been added to the Iberian, African and Native influences. Together, these have molded, to a large extent, our hearts and minds. This paper focuses on the influence of French culture and French conservative Catholicism in the constitution of Brazilian anti-semitism. The analisys of religious iconography reveals one of the sources of the satanization of the Jews in popular and elite imagination. The development of the social exclusion of the French Jews and their deportation to the concentration camps is analysed in the context of a tour around the Marais, the jewish district in
KEY WORDS:

anti-semitism, concentration camps, Drancy,

France. 
Paris. Corbusier's concentrationist architecture completes the social exclusion picture. All of these elements together allow us to understand, to a certain extent, how the image of the immigrant Jew was built and seen by various authors.

\section{REFERÊNCIAS BIBLIOGRÁFICAS}

Barnavi, Elie (org.). (1995). História universal dos judeus. Da gênese ao fim do século XX. Belém/São Paulo, Editora Cejup.

Blay, Eva Alterman. (1989) Inquisição. Inquisições. Tempo Social, São Paulo, 1(1): 105-130.

CAmpos, Humberto. (1933) Em favor de Israel. In: Lima, Márcio Campos (org.). Os judeus na Alemanha. Rio de Janeiro, Flores \& Mano.

Devaux, L. TH. (1939) Prefácio. In: Férenzy, Oscar (org.). Os Judeus e nós Christãos. Trad. de Godofredo Rangel. São Paulo, Companhia Editora Nacional.

FÉrenzy, Oscar (org.). (1939) Os Judeus e nós Christãos. Trad. de Godofredo Rangel. São Paulo, Companhia Editora Nacional.

GreEn, Nancy. (1985). Les travailleurs immigrés juifs à la Belle époque. Fayard, Paris.

KlaRSFEld, Serge. (1978). Le memorial de la déportation des juifs de France. 1942 a 1944. New York, Beate Klarsfeld Foundation.

MANDEL, Arnold. (1950) Les temps incertains. Calman-Levy apud Green,1985

RAPHAËL, Freddy \& WEYL, Robert. (1977) Juifs en Alsace. (Culture, société, histoire). Privat Editeur. Toulouse, France.

Vital-Durand, Brigitte. (1996). Domaine Privé. Paris, Éditions Generales First.

\section{Documentos e centros de documentação pesquisados:}

Camp d'Internement de Drancy. Documento da Prefecture de Police. Archives Nationales. Carton F9 5579. Rapport mai 1943 (document de la direction de la Police Generale). Statistiques. Effectives par categorie. Pag. 1. Effectifs par nationalité. Pag. 3. Mouvements d'Effectives au mois de mai / 1943. Divers: nombre des colis arrivés, argent reçu, visites, correspondance, censure sur correspondence.

Centre de Documentation Juive Contemporaine. Agradeço enormemente às documentalistas Sra. Sarah MIMOUN, Karen TAÏEB, e Lior BITTOUN-SMADJA.

Conservatoire Historique du Camp de Drancy. Cité de la Muette. 15, rue Arthur Fontaine. 93700 Drancy. Agradeço a grande ajuda da historiadora brasileira que trabalha em Drancy, a Prof. Maria de Souza.

Strasbourg Archives Municipales. 